\title{
Quantification in event semantics: Generalized quantifiers vs. sub-events ${ }^{1}$ Sascha ALEXEYENKO — University of Göttingen
}

\begin{abstract}
The goal of this paper is to evaluate two approaches to quantification in event semantics, namely the analysis of quantificational DPs in terms of generalized quantifiers and the analysis proposed in Schein (1993) according to which quantifiers over individuals contain an existential quantifier over sub-events in their scope. Both analyses capture the fact that the event quantifier always takes scope under quantifiers over individuals (the Event Type Principle in Landman (2000)), but the sub-events analysis has also been argued to be able to account for some further data, namely for adverbs qualifying 'ensemble' events and for mixed cumulative/distributive readings. This paper shows that the sub-events analysis also provides a better account of the Event Type Principle if a broader range of data is considered, including cases with non-existential quantifiers over events: unlike the generalized quantifiers analysis, it can successfully account for the interpretation of indefinites in bare habituals and sentences that contain overt adverbs of quantification.
\end{abstract}

Keywords: quantification, event semantics, generic quantifier, habituals, Q-adverbs.

\section{Introduction}

In semantic systems that do not take events to be a basic semantic type, the interpretation and semantic behavior of quantificational DPs (QPs) have been intensely studied and are comparably well understood. QPs are standardly assumed to denote generalized quantifiers, type $\langle e t, t\rangle$, which implies an asymmetry between subjects and non-subjects: differently from subject QPs, non-subjects produce a type clash in their base positions. This type clash is avoided by assuming that non-subject QPs undergo Quantifier Raising (QR) to a position of type $t$ (S/IT/TP or $\mathrm{VP} / v \mathrm{P}$ if subjects are generated $\mathrm{VP} / v \mathrm{P}$-internally), and Quantifier Raising is also used to model quantifier scope ambiguities. This state of affairs is schematically represented below.
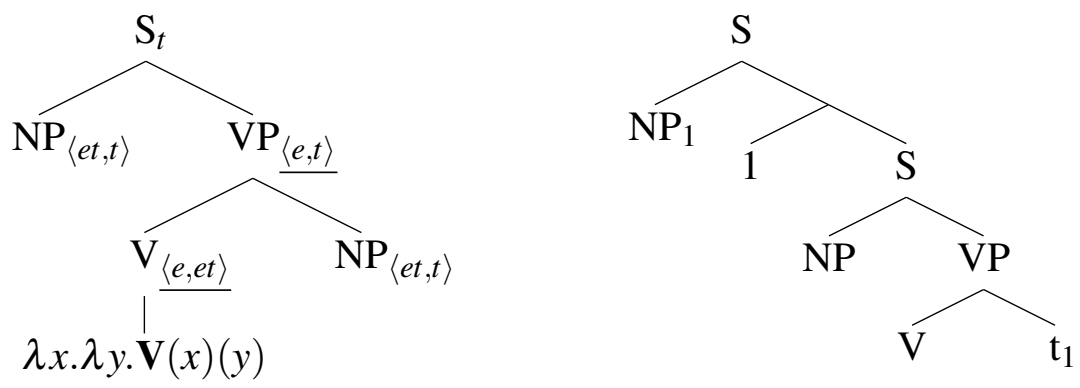

In event semantic frameworks, by contrast, there are more analytical possibilities available as to what quantificational DPs denote and what their semantic type is. To see this, (2) first shows

\footnotetext{
${ }^{1}$ For comments on various versions of this paper, I would like to thank Graham Katz, Jan Köpping, Manuel Križ, Louise McNally, Cécile Meier, Viola Schmitt, Carla Umbach, Hedde Zeijlstra, and the audiences of the Language and Cognition workshop in Osnabrück, the Quantifiers and Determiners workshop in Toulouse, as well as SuB22 in Potsdam/Berlin. I am particularly grateful to Fred Landman, Susan Rothstein, and especially to Ede Zimmermann for discussions on an earlier version of this work.
} 
the type composition in the lower verbal domain of a transitive clause, where $v$ is the type of events. $^{2}$

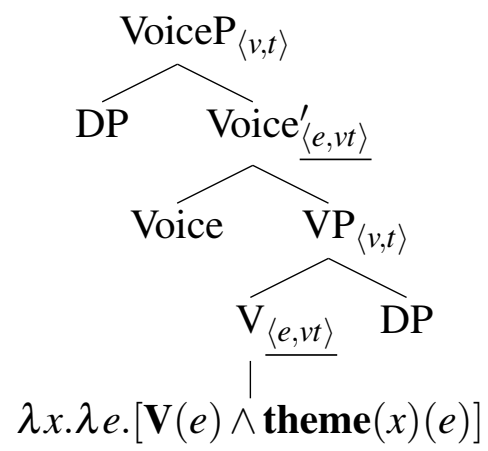

In this configuration, there is no asymmetry anymore between subjects and non-subjects: the sister constituents of the subject and object DPs in (2) have the same semantic type. Despite this difference from eventless frameworks, the analysis of quantificational DPs in terms of generalized quantifiers can be straightforwardly adopted also here, as is done, for instance, in Landman (2000). In this case, being of type $\langle e t, t\rangle$, quantificational subjects and non-subjects alike must for type reasons obligatorily undergo QR to a position of type $t$, i.e. to TP.

However, the type composition in (2) also allows for an alternative treatment of QPs, namely as expressions of type $\langle\langle e, v t\rangle, v t\rangle$. In this case, QR to TP is not possible, but quantificational DPs can be interpreted in situ or be optionally QRed to VoiceP (position of type $\langle v, t\rangle$ ) for scope reasons. This kind of analysis was first proposed in Schein (1993), whose semantics of quantificational DPs contains a variable ranging over 'ensemble' events (sum events) and one ranging over sub-events (part events) and introduces an existential quantifier over sub-events in the scope of the quantifier over individuals. Thus, while the generalized quantifier semantics of, e.g., every girl is as in (3), Schein's semantics of it is as in (4), where $\sqsubseteq$ is a part-of relation.

$$
\begin{aligned}
& \llbracket \text { every } \operatorname{girl} \rrbracket=\lambda P \cdot \forall x[\operatorname{girl}(x) \rightarrow P(x)] \\
& \llbracket \text { every girl } \rrbracket=\lambda P \cdot \lambda e \cdot \forall x\left[\operatorname{girl}(x) \rightarrow \exists e^{\prime}\left[e^{\prime} \sqsubseteq e \wedge P(x)\left(e^{\prime}\right)\right]\right]
\end{aligned}
$$

Both analyses capture the fact that the event quantifier always takes scope under quantifiers over individuals (cf. the Event Type Principle in Landman (2000)): due to obligatory QR to $\mathrm{TP}$ in the generalized quantifier analysis (GQ analysis, henceforth) and due to the presence of an existential quantifier over sub-events in the sub-event analysis (SE analysis, henceforth). However, the SE analysis has also been argued to be able to account for some further data, namely for adverbs qualifying ensemble events and for mixed cumulative/distributive readings (cf. Schein, 1993; Kratzer, 2002; Ferreira, 2005), which will be discussed in more detail below in section 2.

The goal of this paper is to show that, in fact, the SE analysis also provides a better account of the Event Type Principle if a broader range of data is considered. So far, it has mainly been

\footnotetext{
${ }^{2}$ Here and below, I do not differentiate between $v \mathrm{P}$ (Chomsky, 1995) and VoiceP (Kratzer, 1996), whose role is to introduce the external argument in their specifier positions.
} 
cases involving a universal quantifier over individuals and an existential quantifier over events (i.e., episodic interpretation) that have been looked at when comparing the GQ analysis and the SE analysis. The paper extends the scope of this comparison to the inverse configuration, that is, to cases with an existential quantifier over individuals and a generic or universal quantifier over events, and shows that the SE analysis but not the GQ analysis can successfully account for the interpretation of indefinites in bare habituals and in sentences that contain overt adverbs of quantification.

The structure of the paper is as follows. Section 2 introduces the SE analysis and discusses the advantages that it has been claimed to have over the more traditional GQ analysis. Section 3 presents data concerning bare habituals and sentences with adverbs of quantification which have not been considered yet in connection with the comparison between the GQ analysis and the SE analysis and which form the empirical basis of the paper. Subsequently, sections 4 and 5 discuss two alternative approaches to the semantics of habituality and evaluate the GQ analysis and the SE analysis with respect to how successful they are in modeling the interpretation of indefinites in bare habituals and overtly quantified sentences, given that these approaches to habituality are adopted. In particular, section 4 shows that neither of the two analyses produces the desired results if a quantificational approach to habituality in terms of a generic quantifier is adopted. In turn, section 5 presents an alternative non-quantificational approach to habituality and shows that in combination with it, the SE analysis can successfully account for the semantic behavior of indefinites in bare habituals and overtly quantified sentences, whereas the GQ analysis cannot. Section 6 concludes.

\section{Quantification and events}

This section introduces the main features of the SE analysis of QPs in comparison with the more traditional GQ analysis and the reasons why it has been proposed. As has already been discussed in the introduction, the type composition in (2) allows QPs to be of type $\langle\langle e, v t\rangle, v t\rangle$. Given this semantic type, the QP every girl could have the following denotation, which would be only a small departure from the standard GQ semantics in (3):

$$
\llbracket \text { every girl } \rrbracket=\lambda P . \lambda e . \forall x[\operatorname{girl}(x) \rightarrow P(x)(e)]
$$

Quantificational DPs of this semantic type can either be interpreted in situ, or they can undergo optional QR to a position of type $\langle v, t\rangle$ (for instance, VoiceP), i.e. a position at which the event argument is not quantified over yet. This implies that quantifiers over individuals introduced by such QPs will always be in the scope of the event quantifier. However, the event quantifier has been observed to take the lowest scope possible with respect to other scope-taking elements such as other quantifiers or negation (cf. Schein, 1993; Landman, 2000), as the examples below demonstrate. $^{3}$

(6) John kissed every girl.
a. $\forall x \gg \exists e$
b. $* \exists e \gg \forall x$

${ }^{3}$ Throughout the paper, ' $\gg$ ' means 'has scope over'. 
(7)

John didn't kiss Mary.

a. $\neg \gg \exists e$

b. $* \exists e \gg \neg$

This fact, which, following Landman (2000), I will call the Event Type Principle, is straightforwardly accounted for by the GQ analysis insofar as it requires QPs to undergo obligatory QR to a position of type $t$, i.e. above the event quantifier. By contrast, the semantics in (5) fails to account for the Event Type Principle, and for this reason Schein (1993) argues that an $\langle\langle e, v t\rangle, v t\rangle$ type semantics of QPs should rather be as below (repeated from (4)):

$$
\llbracket \text { every } \operatorname{girl} \rrbracket=\lambda P . \lambda e . \forall x\left[\operatorname{girl}(x) \rightarrow \exists e^{\prime}\left[e^{\prime} \sqsubseteq e \wedge P(x)\left(e^{\prime}\right)\right]\right]
$$

Instead of containing just one variable ranging over events, the semantics in (8) contains two: one over 'ensemble' events (sum events) and one over their sub-events. The single event variable in standard (neo-)Davidsonian event semantics corresponds here to the variable ranging over sub-events, which is existentially quantified over in the nuclear scope of quantifiers over individuals. This is precisely what accounts for the Event Type Principle in this framework.

Before proceeding to the advantages that this analysis has been argued to have, I should note that, in fact, the semantics in (8) is too weak, as pointed out by Ferreira (2005). This is because it places no restrictions on the identity of the 'ensemble' events: thus e.g. in (6), the sum event containing individual events of kissing of a girl by John should be an event of girl-kissing by John itself, while (8) would give us that the sum event can be any event that contains events of kissing of a girl by John as its sub-events, even if it also contains other kinds of sub-events. For this reason, Ferreira (2005) suggests that Schein's semantics of QPs should be modified such that it includes a further restriction on the sub-events which ensures that they are all of the right kind:

$$
\begin{aligned}
& \llbracket \text { every girl } \rrbracket=\lambda P \cdot \lambda e \cdot\left[\forall x [ \operatorname { g i r l } ( x ) \rightarrow \exists e ^ { \prime } [ e ^ { \prime } \sqsubseteq e \wedge P ( x ) ( e ^ { \prime } ) ] ] \wedge \forall e ^ { \prime } \left[e^{\prime} \sqsubset e \rightarrow \exists x[\operatorname{girl}(x) \wedge\right.\right. \\
& \left.\left.\left.P(x)\left(e^{\prime}\right)\right]\right]\right]
\end{aligned}
$$

Both Schein's semantics in (8) and Ferreira's semantics in (9) get the scope facts (i.e. the Event Type Principle) right, as is shown below for John kissed every girl using the denotation in (9) and ignoring tense.

$$
\begin{array}{lll}
\text { a. } & \text { John kissed every girl. } & \exists e \gg \forall x \gg \exists e^{\prime} \\
\text { b. } & \exists e[\operatorname{agent}(\text { john })(e) & \\
& \wedge \forall x\left[\operatorname{girl}(x) \rightarrow \exists e^{\prime}\left[e^{\prime} \sqsubseteq e \wedge \operatorname{kiss}\left(e^{\prime}\right) \wedge \text { theme }(x)\left(e^{\prime}\right)\right]\right] \\
& \left.\wedge \forall e^{\prime}\left[e^{\prime} \sqsubset e \rightarrow \exists x\left[\operatorname{girl}(x) \wedge \operatorname{kiss}\left(e^{\prime}\right) \wedge \operatorname{theme}(x)\left(e^{\prime}\right)\right]\right]\right]
\end{array}
$$

However, the original motivation for the SE analysis hasn't been to account for the Event Type Principle: the GQ analysis can account for it in a much simpler way. The reason why Schein proposed this analysis is that it can also account for some further data which are problematic for the standard GQ analysis, namely adverbs qualifying ensemble events and mixed cumulative/distributive readings. Adverbs that qualify ensemble events are illustrated in the examples 
below from Schein (1993):

(11) a. In slow progression, every organ student struck a note on the Wurlitzer.

b. Unharmoniously, every organ student sustained a note on the Wurlitzer for sixteen measures.

Each of the individual events of striking/sustaining of a note by an organ student cannot occur in slow progression, nor can it be harmonious or unharmonious; adverbials like in slow progression and unharmoniously can apply to sequences of events (i.e. plural events), but not to singular events. Now, the logical forms of the sentences above that employ the semantics for every organ student along the lines of (8) or (9) contain a variable ranging over sum events, so adverbials like in slow progression and unharmoniously can modify the sum event containing sub-events of individual organ students striking/sustaining a note. By contrast, no such variable is available in the representations provided by standard (neo-)Davidsonian event semantics, and hence in slow progression and unharmoniously can only apply to the individual striking/sustaining events.

Another argument in favor of the SE analysis comes from mixed cumulative/distributive readings, which Schein (1993) illustrates with examples such as the following one (see also Kratzer, 2002):

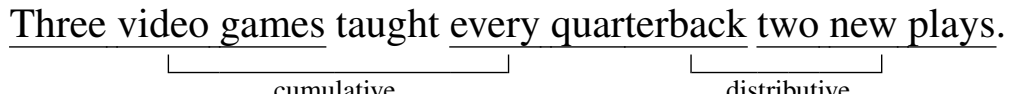

This sentence has a reading according to which three video games is interpreted cumulatively, whereas every quarterback is interpreted distributively with two new plays in its scope: three video games (between them) taught every quarterback two (other) new plays. Neo-Davidsonian event semantics, which separates the external argument as a distinct theta-role predicate, combined with the semantics for QPs along the lines of (8)/(9), which introduces two event variables, can account for this interpretation, as the logical form below from Ferreira (2005: 25) demonstrates (again, tense is ignored):

$$
\begin{aligned}
& \exists e \exists X[\operatorname{videogame}(X) \wedge|X|=3 \wedge \operatorname{agent}(X)(e) \\
& \wedge \forall y\left[\text { quarterback } ( y ) \rightarrow \exists e ^ { \prime } \left[e^{\prime} \sqsubseteq e \wedge \operatorname{to}(y) \underline{\left(e^{\prime}\right)} \wedge \exists Z[\operatorname{newplay}(Z) \wedge|Z|=2\right.\right. \\
& \left.\left.\left.\wedge \text { theme }(Z)\left(e^{\prime}\right) \wedge \operatorname{teach}\left(e^{\prime}\right)\right]\right]\right] \\
& \wedge \forall e^{\prime}\left[e ^ { \prime } \sqsubset e \rightarrow \exists y \left[\operatorname{quarterback}(y) \wedge \operatorname{to}(y) \underline{\left(e^{\prime}\right)} \wedge \exists Z[\operatorname{newplay}(Z) \wedge|Z|=2\right.\right. \\
& \left.\left.\left.\left.\wedge \operatorname{theme}(Z)\left(e^{\prime}\right) \wedge \operatorname{teach}\left(e^{\prime}\right)\right]\right]\right]\right]
\end{aligned}
$$

Video games act here as the agent of the 'ensemble' event, whereas both quarterbacks and new plays are participants in the sub-events, and this is what allows to capture the mixed cumulative/distributive pattern. By contrast, this is not possible in an event semantic framework which does not separate the agent theta-role and does not introduce a variable ranging over 'ensemble' events. $^{4}$

\footnotetext{
${ }^{4}$ See Champollion (2010), who shows that mixed cumulative/distributive readings can also be accounted for in eventless frameworks.
} 
The goal of this paper is to show that, in fact, the SE analysis also provides a better account of the Event Type Principle than the GQ analysis if, in addition to cases involving a universal quantifier over individuals and an existential event quantifier, inverse cases with an existential quantifier over individuals and a generic or universal event quantifier are considered as well. Hence, the next section presents data concerning the interpretation of indefinites in bare habituals and in sentences that contain overt adverbs of quantification.

\section{Bare habituality vs. overt quantification}

\subsection{Interpretation of indefinites}

This section introduces the first crucial piece of data, which concerns the semantic behavior of indefinites in bare habituals and in sentences containing overt adverbs of quantification, more specifically, the availability of narrow scope readings of indefinites in these contexts.

The semantics of bare habitual sentences, such as the ones in (14) below, is usually assumed to contain a silent generic quantifier GEN (see, e.g., Krifka et al., 1995), an unpronounced generic counterpart of overt adverbs of quantification (Q-adverbs) like always or often.
a. John smokes.
b. John smokes a pipe.
c. John smokes cigarettes.

Quantificational adverbs like always as well as quantificational adverbials like every morning introduce quantifiers over events or times ${ }^{5}$, which enter into scope relations with other quantifiers, as the sentences below with the singular indefinite a cigarette demonstrate. Hence, both scope configurations are available in these examples, even though only one of them is pragmatically felicitous: the wide scope reading of a cigarette suggests that the same cigarette is repeatedly smoked over a long period of time, which is in conflict with world knowledge (notice that, by contrast, a pipe or the plural indefinite cigarettes are pragmatically fine).

\section{John smokes a cigarette every morning.}

John always smokes a cigarette.
a. $\# \exists \gg \forall$
b. $\forall \gg \exists$

If GEN is indeed a quantifier like the one introduced by always or every morning, one would expect bare habituals containing indefinites to display analogous scope ambiguities. However, this does not seem to be the case, as examples like (16) suggest: while the wide scope reading of a cigarette is pragmatically infelicitous like before (notice that the bare habitual with a pipe in (14) is fine), the fact that (16) is odd altogether suggests that the narrow scope reading of $a$ cigarette is not available for some reason, as has been repeatedly pointed out in the literature

\footnotetext{
${ }^{5}$ In later sections, I will argue that Q-adverb(ial)s like always and every morning introduce quantification over times. For now I am staying neutral in this respect however, given that it is commonly assumed that Q-adverbs quantify over events.
} 
(possibly the earliest mentioning of this fact can be found in Carlson (1977)). ${ }^{6}$

(16) \#John smokes a cigarette.

a. $\# \exists \gg$ GEN

Note that, under the assumption that (16) contains the generic quantifier GEN, the scope facts in (16) seem to be just another manifestation of the Event Type Principle discussed above: the event quantifier (in this case, GEN) takes the lowest scope possible with respect to quantifiers over individuals. In the literature on genericity and habituality, the obligatory wide scope of indefinites in bare habituals has often been accounted for by assuming that there is something special about GEN as compared to overt Q-adverbs. One possibility, explored in Cohen (2013), is to assume that the null generic quantifier differs from overt adverbs of quantification insofar as it is introduced by type-shifting, whence its narrow scope. More commonly, however, a more radical departure from the analysis of bare habituals in terms of GEN is entertained, whereby they are assumed to contain a scopeless non-quantificational generic operator, rather than the generic quantifier GEN (for various versions of this analysis, see Carlson, 1977; Rimell, 2004; van Geenhoven, 2004; Ferreira, 2005; Kratzer, 2008; Boneh and Doron, 2013). Sections 4 and 5 will discuss both the quantificational and the non-quantificational treatment of bare habituals in more detail. Before we get there, however, another important piece of data concerning bare habituals needs to be introduced.

\subsection{Q-adverbs in habituals}

Another crucial piece of data concerning habituals has to do with the fact that, in languages which have specialized habitual tense forms, these tense forms can combine with adverbs of quantification. This can be seen even in English, which does not have rich aspectual morphology, in the case of simple present habituals and, more clearly, the used to construction, as the examples below show:
a. John used to smoke.
b. *John used to smoke once/yesterday.
c. John used to smoke every day.
d. John used to always smoke (on the phone).

The incompatibility of the used to form with adverbs like once and yesterday shows that it is a

\footnotetext{
${ }^{6}$ Note that sentences like (16) are fine in the presence of overt or implicit (contextually specified) restrictors, as the examples below demonstrate:

I won't be concerned with such cases in this paper, simply assuming that they contain a silent always as a default adverb of quantification (Lewis, 1975), which is licensed if an overt or implicit restrictor is present. In this way, the examples above are just a sub-case of the paradigm in (15).
} 
specialized habitual form, which cannot occur in episodic environments. On the other hand, it is perfectly compatible with adverbs of quantification, such as always and every day. The same is of course also true of the simple present form, which occurs not only in bare habituals, but also in sentences containing adverbs of quantification.

This fact holds in a more transparent way for languages with richer aspectual morphology that have specialized habitual marking, such as, for instance, Hindi/Urdu and Ewe, cf. the examples below. In particular, the specialized habitual morpheme -taa in Hindi/Urdu can co-occur with quantificational adverbials like every day; in fact, the habitual aspect must be used when such adverbials are present. The same holds for the habitual marker -na in Ewe.

Raam (roz /*ek baar /*kal) sigret pii-taa thaa.

R. every_day one time yesterday cigarette drink-HAB be.PAST

'Ram smoked/would smoke (every day/*once/*yesterday).'

$(\text { Hindi/Urdu) })^{7}$

Agbenyo yi-na suku ydi sia ydi.

A. go-HAB school morning that morning

'Agbenyo goes to school every morning.'

$(\text { Ewe })^{8}$

The fact that the habitual verbal morphology is not only compatible with adverbs of quantification, but is even required in their presence, is often not taken into consideration in the analyses of the semantics of habituality. However, this fact is crucial for understanding habitual semantics, given that the habitual morphology should be attempted to be given a unified analysis across its uses in bare habituals and habituals with overt adverbs of quantification. In particular, the problem is that it is not immediately clear how to avoid double event plurality without assuming semantic inertness of habitual markers in the presence of Q-adverbs. The next section will show that this is a serious problem for a quantificational analysis of habituals.

\section{Quantificational analysis of habituals}

\subsection{The GQ analysis}

This section discusses the quantificational analysis of habituals and shows that, in combination with the GQ analysis of QPs, it fails to adequately model the semantic behavior of indefinites in bare habituals and habituals containing adverbs of quantification in a unified way.

Let us first spell out the quantificational analysis of habituals based on the silent generic quantifier GEN in somewhat more precise terms. GEN is usually assumed to be a modalized quantifier with quasi-universal force, which is designed to account for such properties of generics as, e.g., their non-accidental law-like nature and their tolerance to exceptions (cf. Dahl, 1975; Chierchia, 1995; Krifka et al., 1995; Cohen, 1999; Greenberg, 2003). Furthermore, given that the habitual is a variety of the imperfective aspect, it is plausible to assume that its semantics is introduced by a special aspectual head. On the quantificational analysis of habituals, the

\footnotetext{
${ }^{7}$ Gurmeet Kaur, p.c.

${ }^{8}$ Agbojo and Litvinov (1997).
} 
denotation of this habitual Asp head, which is null in English, may be formalized for example along the following lines:

$$
\llbracket \mathrm{HAB} \rrbracket=\lambda P . \lambda t . \exists e\left[t \subseteq \tau(e) \wedge \mathrm{GEN} e^{\prime}\left[e^{\prime} \sqsubseteq e \wedge \mathbf{C}\left(e^{\prime}\right)\right]\left[P\left(e^{\prime}\right)\right]\right]
$$

Like any imperfective head, HAB takes a property of events, quantifies over the event variable, maps the event to its run time by means of the temporal trace function $\tau$ (cf. Krifka, 1989), and relates the event time to some reference time $t$, such that the reference time is included in the event time (cf. Reichenbach, 1947; Klein, 1994; Giorgi and Pianesi, 1997; Kratzer, 1998). What is special about HAB in (20) as compared to other imperfective heads is that the event quantifier is generic rather than existential and that the reference time is located within the run time of the entire habitual sequence rather than any of its sub-events. ${ }^{9}$

Now, given the denotation of HAB in (20), the GQ analysis unproblematically accounts for the obligatory wide scope of indefinites in bare habituals and, thus, for the pragmatic infelicity of sentences like John smokes a cigarette: because of the obligatory QR of QPs above the event quantifier, the only scope configuration it can derive for such sentences is $\exists x \gg$ GENe. What is more, this scope configuration gets derived without any further assumptions (such as, e.g., type-shifting in Cohen (2013)), since QPs must undergo QR above the generic quantifier, while the aspectual head HAB, which introduces the generic quantifier, cannot be QRed.

However, the GQ analysis encounters a problem with habitual sentences containing adverbs of quantification under the assumption that also such sentences contain HAB, as the data discussed in the previous section suggest. Thus, for instance, John smokes a cigarette every morning would have the following two scope possibilities if the GQ analysis is adopted in combination with the semantics of HAB in (20):

John smokes a cigarette every morning.
a. $\forall \gg \exists \gg$ GEN
b. $\quad \exists \gg \forall \gg$ GEN

In both cases, there is too much event plurality: both of the readings imply that a habitual series of smoking events occurs per morning, yielding an unusual short-lived habituality. Moreover, in both cases the indefinite takes scope over the generic quantifier, which should result in pragmatic infelicity, contrary to fact.

Note, finally, that this problem of double event plurality is not restricted to cases with adverbs of quantification, but also occurs when other, non-temporal quantifiers are present, as, e.g., in the example below. Again, the readings that this sentence is predicted to have imply that John habitually smokes in each of the pubs.

(22) John smokes a cigarette in every pub he walks into.

\footnotetext{
${ }^{9}$ The semantics of HAB does not necessarily need to be formalized in such a way that it contains a variable over sum events, i.e., the entire habitual sequences, like in (20). Alternatively, it can also be defined by means of convex closures (cf., e.g., Boneh and Doron, 2008).
} 
Intuitively, the situation could be saved if the event quantifier was existential in such cases, i.e. if the aspectual head contributed an episodic semantics. This would mean, however, that the habitual morphology will have to have a different semantics in sentences containing adverbs of quantification and other quantifiers introducing pluralities than its semantics in bare habituals, and thus a unified analysis of habituality would not be possible.

\subsection{The SE analysis}

The quantificational approach to habituals faces the problem of double event plurality in combination with the SE analysis of QPs in the same way as it does in combination with the GQ analysis. In addition, however, it also fails to account for the semantic scope of indefinites in bare habituals-something that the GQ analysis has no problems with, as we have seen in the previous section. In particular, given the semantic type of QPs on the SE analysis $(\langle\langle e, v t\rangle, v t\rangle)$, they can only be QRed to positions below the event quantifier, if they undergo QR at all. Yet this implies that bare habitual sentences like John smokes a cigarette will always get the scope configuration GENe $\gg \exists x$, and so should be pragmatically fine, contrary to fact. What is more, it is not clear how to derive the wide scope readings of indefinites in bare habituals at all.

The scope configuration that we would want for bare habitual sentences on the SE analysis is rather $\exists e \gg \exists x \gg \mathrm{GEN} e^{\prime}$, where existential quantification over sum events is contributed by the aspectual head, whereas generic quantification over sub-events is introduced in the nuclear scope of quantifiers over individuals, as proposed by Schein (1993). However, this would mean that quantificational determiners $a$, every, and so on, will have to be assumed to be ambiguous between two meanings that differ only with respect to the event quantifier that these determiners host in their nuclear scope, namely one with an existential and one with a generic quantifier. In addition, it would also be unclear how to motivate the fact that habitual morphology contributes existential quantification over events.

Thus, independently of the choice of the analysis of QPs, the analysis of habituality in terms of the generic quantifier does not seem to allow for a unified account of the semantic behavior of indefinites in bare habituals and in habituals containing overt quantification. The next section will consider an alternative, non-quantificational approach to habituality.

\section{Non-quantificational analysis of habituals}

\subsection{Habituals as sum events}

The semantics of habituals has a common alternative analysis to the one in terms of the generic quantifier GEN. According to it, a habitual series should be modeled as a sum of (proper) part events, rather than as quantification over events. There are various implementations of this idea in the literature (cf. Carlson, 1977; Rimell, 2004; van Geenhoven, 2004; Ferreira, 2005; Kratzer, 2008; Boneh and Doron, 2013), which differ in the details of the proposed semantics of habitual sentences. For the purposes of this paper, these details are not crucial, as the focus of the paper is on the comparison between the GQ analysis and the SE analysis with respect 
to certain data concerning habituals, rather than on the semantics of habituals as such. Hence, concentrating on the core idea of the non-quantificational treatment of habituals as plural events and glossing over a lot of other details concerning their semantics, the denotation of the nonquantificational version of the habitual aspectual head HAB may be formalized in the following way, where $\sigma$ is the sum operator:

$$
\llbracket \mathrm{HAB} \rrbracket=\lambda P . \lambda t . \exists e\left[t \subseteq \tau(e) \wedge e=\sigma e^{\prime}\left[\operatorname{stage}\left(e^{\prime}\right)(e)\right] \wedge P(e)\right]
$$

Note that the semantics in (23) states that the individual events within the habitual series are its stages rather than just parts, that is, it employs the stage-of relation, which has been proposed in Landman (1992) to model the semantics of progressives. This reflects a common view in the literature that, being two varieties of the imperfective, the progressive and the habitual should be modeled alike (e.g., in terms of inertia futures) and that the only difference between them is that PROG selects sets of singular events, while HAB selects sets of plural events (cf. Ferreira, 2005; Deo, 2009; Altshuler, 2014). Here, the complex modal-temporal semantics of habituality will be abbreviated into the predicate stage.

Equipped with the semantics of HAB in (23), we can now see whether the two analyses of QPs in combination with the non-quantificational approach to habituality are able to account for the semantic behavior of indefinites in bare habituals and in habituals containing overt adverbs of quantification in a unified way.

\subsection{Bare habituals}

Let us start with bare habituals, using again John smokes a cigarette as a test example. Before spelling out its semantics under the GQ and SE analyses, (24) first illustrates my assumptions with respect to the basic syntactic architecture of a transitive clause and the corresponding type composition (cf., e.g., Giorgi and Pianesi, 1997; Kratzer, 1998; Alexiadou et al., 2003). Here, $i$ is the type of times, or, more precisely, time intervals.

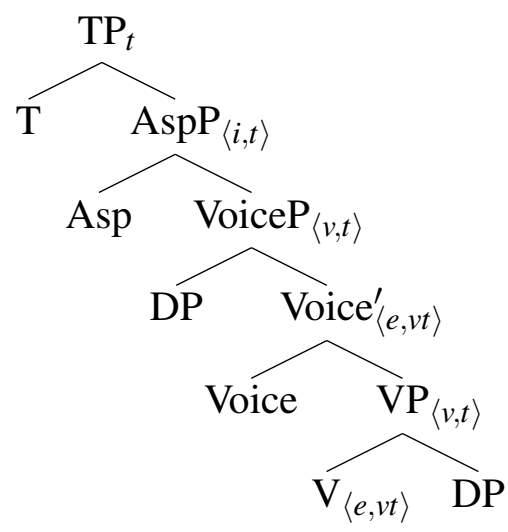

It has already been mentioned before that the aspectual head Asp relates the event time to the reference time. By contrast, the function of the tense head $\mathrm{T}$ is to relate the reference time and the utterance time. Accordingly, the locus of event time adverbials (such as, e.g., on Monday, 
but also every morning and always) is VP/VoiceP, the locus of reference time adverbials (e.g., by tomorrow or until July 18) is AspP, while the locus of utterance time adverbials (e.g., now) is TP.

Now, given the syntax in (24), the LF of John smokes a cigarette under the GQ analysis will be as in (25), where a cigarette undergoes obligatory QR to TP for type reasons. (26) provides the interpretation we get for this LF using the non-quantificational denotation of HAB in (23) and assuming that PRES in matrix clauses denotes the deictic pronoun now referring to the time of utterance (cf., e.g., von Stechow, 2009). ${ }^{10}$

$$
\begin{aligned}
& \left.\left.\left[\mathrm{TP}[\text { a cigarette }]_{1} \lambda_{1}\left[\mathrm{TP} \text { PRES [AspP HAB [VoiceP John smoke } \mathrm{t}_{1}\right]\right]\right]\right] \\
& \exists x\left[\boldsymbol{\operatorname { c i g a r e t t e }}(x) \wedge \exists e\left[\mathbf{n o w} \subseteq \tau(e) \wedge e=\sigma e^{\prime}\left[\operatorname{stage}\left(e^{\prime}\right)(e)\right] \wedge \operatorname{smoke}(x)(\mathbf{j o h n})(e)\right]\right]
\end{aligned}
$$

This semantics adequately represents the pragmatically infelicitous reading that John smokes a cigarette has: it states that the same cigarette is smoked in the entire habitual series. Moreover, no other scope possibility is available in this case, as desired.

In fact, the situation is not much different under the SE analysis, as (27) and (28) below show: even though a cigarette can now be interpreted in situ (or be QRed to VoiceP, which would be truth-conditionally equivalent), nothing changes in its 'wide' scope relation with respect to the sum operator, and therefore the pragmatically odd reading obtains as the only possibility. ${ }^{11}$

$$
\begin{aligned}
& \text { [TP PRES [AspP HAB [VoiceP John smoke a cigarette]]] } \\
& \exists e\left[\text { now } \subseteq \tau(e) \wedge e=\sigma e^{\prime}\left[\operatorname{stage}\left(e^{\prime}\right)(e)\right] \wedge \exists x[\operatorname{cigarette}(x) \wedge \operatorname{smoke}(x)(\text { john })(e)]\right]
\end{aligned}
$$

Thus, in combination with a non-quantificational approach to habituality, both analyses of QPs are able to account for the wide scope of indefinites in bare habituals.

\subsection{Overt quantification}

Let us now turn to habituals containing overt adverbs of quantification, such as John smokes a cigarette every morning. As already mentioned above, I assume that phrases like every morning are (quantificational) event time adverbials, and thus are VP/VoiceP-adjuncts. Furthermore, I also assume that they are in fact PPs, whose null $\mathrm{P}$ head relates the time they introduce to the run time of the event, as shown below (Q-adverbs such as always are treated in the same way, being the spell-out of phrases like 'all times'/'every time').

$$
\text { [PP P [DP every morning]] }
$$

\footnotetext{
${ }^{10}$ To make the semantic formulae below more readable, I will represent the meaning of verbs with $n$ syntactic arguments as $n$-ary relations, instead of representing their arguments as separate $\theta$-role conjuncts.

${ }^{11}$ Indefinites don't introduce quantification over sub-events in the nuclear scope of the existential quantifier (cf. Schein, 1993; Ferreira, 2005); thus, the denotation of a cigarette is $\lambda P . \lambda e . \exists x[$ cigarette $(x) \wedge P(x)(e)]$. Note that if a cigarette had a denotation along the lines of (9), it would get a narrow scope in bare habituals.
} 


$$
\llbracket \mathrm{P} \rrbracket=\lambda t . \lambda P . \lambda e .[P(e) \wedge \tau(e) \subseteq t]
$$

Now, under the GQ analysis, both a cigarette and every morning denote generalized quantifiers (the latter over times: $\lambda P \cdot \forall t[$ morning $(t) \rightarrow P(t)]$ ) and thus have to undergo QR to TP. Below the interpretation which John smokes a cigarette every morning gets under this analysis is shown, with every morning scoping above a cigarette:

(31) $\quad[\text { те [every morning }]_{2} \lambda_{2}\left[\right.$ тт $[\text { a cigarette }]_{1} \lambda_{1}[$ те PRES [AspP HAB [VoiceP John smoke $\left.\left.\left.\left.\mathrm{t}_{1}\left[\mathrm{PP}_{\mathrm{P}} \mathrm{t}_{2}\right]\right]\right]\right]\right]$

$$
\begin{aligned}
& \forall t\left[\operatorname { m o r n i n g } ( t ) \rightarrow \exists x \left[\text { cigarette } ( x ) \wedge \exists e \left[\text { now } \subseteq \tau(e) \wedge e=\sigma e^{\prime}\left[\operatorname{stage}\left(e^{\prime}\right)(e)\right]\right.\right.\right. \\
& \wedge \operatorname{smoke}(x)(\text { john })(e) \wedge \tau(e) \subseteq t]]]
\end{aligned}
$$

This semantics is problematic for several reasons. First, it states that there is a habitual series of smoking events per morning, which is not the most natural interpretation of John smokes a cigarette every morning, if this sentence has that reading at all. Moreover, the same cigarette is smoked in all sub-events of each of such habitual sum events, which should trigger pragmatic infelicity, contrary to fact. And finally, the run time of each of these habitual events is included in the time of the respective morning, but at the same time, the run times of all of them include now (i.e., these are ongoing events), which is difficult to make sense of. Note that the inverse scope possibility (with a cigarette scoping above every morning) is available as well, but does not make things better.

Let us now see what happens under the SE analysis. The denotation of every morning will be in this case as below (cf. (9)):

$$
\begin{aligned}
& \llbracket \text { every morning } \rrbracket=\lambda P . \lambda e \cdot\left[\forall t [ \operatorname { m o r n i n g } ( t ) \rightarrow \exists e ^ { \prime } [ e ^ { \prime } \sqsubseteq e \wedge P ( t ) ( e ^ { \prime } ) ] ] \wedge \forall e ^ { \prime } \left[e^{\prime} \sqsubset e \rightarrow\right.\right. \\
& \left.\left.\exists t\left[\operatorname{morning}(t) \wedge P(t)\left(e^{\prime}\right)\right]\right]\right]
\end{aligned}
$$

If a cigarette is interpreted in situ and every morning undergoes QR to VoiceP, John smokes a cigarette every morning gets the following interpretation:

(34) $\quad[\text { Tе PRES [AspP HAB [VoiceP [every morning }]_{1} \lambda_{1}$ [VoiceP John smoke a cigarette [PP $\left.\left.\left.\left.\left.\mathrm{t}_{1}\right]\right]\right]\right]\right]$

$$
\begin{aligned}
& \exists e\left[\text { now } \subseteq \tau(e) \wedge e=\sigma e^{\prime}\left[\operatorname{stage}\left(e^{\prime}\right)(e)\right]\right. \\
& \wedge \forall t\left[\operatorname{morning}(t) \rightarrow \exists e^{\prime}\left[e^{\prime} \sqsubseteq e \wedge \exists x\left[\operatorname{cigarette}(x) \wedge \operatorname{smoke}(x)(\text { john })\left(e^{\prime}\right)\right] \wedge \tau\left(e^{\prime}\right) \subseteq t\right]\right] \\
& \left.\wedge \forall e^{\prime}\left[e^{\prime} \sqsubset e \rightarrow \exists t\left[\operatorname{morning}(t) \wedge \exists x\left[\operatorname{cigarette}(x) \wedge \operatorname{smoke}(x)(\text { john })\left(e^{\prime}\right)\right] \wedge \tau\left(e^{\prime}\right) \subseteq t\right]\right]\right]
\end{aligned}
$$

The semantics above adequately captures the most natural reading of John smokes a cigarette every morning. It states that there is an ongoing habitual series of smoking events whose subevents distribute over mornings, and that there is a potentially different cigarette that is smoked in each of the morning smoking events. This is the pragmatically fine narrow scope reading of a cigarette; the pragmatically infelicitous wide scope reading can be captured as well, as desired, if a cigarette is QRed above every morning. 
Thus, this shows that only the SE analysis is able to provide an adequate semantics for habitual sentences containing overt adverbs of quantification, provided that a non-quantificational approach to habituality is adopted, while the GQ analysis is not.

\section{Conclusion}

This paper has shown that, if a non-quantificational approach to habituality is adopted, the GQ analysis and the SE analysis of QPs are not equally suitable for event semantics, as only the latter successfully accounts for the semantic behavior of indefinites in bare habituals and in habituals containing overt adverbs of quantification in a unified way. This is a further argument, in addition to the existing arguments from adverbs qualifying 'ensemble' events and mixed cumulative/distributive readings, in favor of an analysis of quantificational DPs that makes use of sub-events.

\section{References}

Agbojo, K. and V. Litvinov (1997). The expression of action plurality in Ewe. In V. Xrakovskij (Ed.), Typology of iterative constructions, pp. 189-202. Munich and Newcastle: Lincom Europa.

Alexiadou, A., M. Rathert, and A. von Stechow (Eds.) (2003). Perfect explorations. Berlin: Mouton de Gruyter.

Altshuler, D. (2014). A typology of partitive aspectual operators. Natural Language and Linguistic Theory 32(3), 735-775.

Boneh, N. and E. Doron (2008). Habituality and the habitual aspect. In S. Rothstein (Ed.), Theoretical and Crosslinguistic Approaches to the Semantics of Aspect, pp. 321-347. Amsterdam: John Benjamins.

Boneh, N. and E. Doron (2013). Hab and Gen in the expression of habituality. In A. Mari, C. Beyssade, and F. Del Prete (Eds.), Genericity, pp. 176-191. Oxford: Oxford University Press.

Carlson, G. (1977). Reference to kinds in English. University of Massachusetts: Ph.D. dissertation.

Champollion, L. (2010). Cumulative readings of every do not provide evidence for events and thematic roles. In M. Aloni, H. Bastiaanse, T. de Jager, and K. Schulz (Eds.), Logic, Language and Meaning: 17th Amsterdam Colloquium, Amsterdam, The Netherlands, December 16-18, 2009, Revised Selected Papers, pp. 213-222. Berlin: Springer.

Chierchia, G. (1995). Individual-level predicates as inherent generics. In G. Carlson and F. Pelletier (Eds.), The Generic Book, pp. 176-223. Chicago, IL: University of Chicago Press.

Chomsky, N. (1995). The Minimalist Program. Cambridge, MA: MIT Press.

Cohen, A. (1999). Think Generic! The Meaning and Use of Generic Sentences. Stanford, CA: CSLI Publications.

Cohen, A. (2013). No quantification without reinterpretation. In A. Mari, C. Beyssade, and F. Del Prete (Eds.), Genericity, pp. 334-351. Oxford: Oxford University Press.

Dahl, O. (1975). On generics. In E. Keenan (Ed.), Formal Semantics of Natural Language, pp. 99-111. Cambridge: Cambridge University Press. 
Deo, A. (2009). Unifying the imperfective and the progressive: partitions as quantificational domains. Linguistics and Philosophy 32(5), 475-521.

Ferreira, M. (2005). Event quantification and plurality. MIT: Ph.D. dissertation.

van Geenhoven, V. (2004). For-adverbials, frequentative aspect, and pluractionality. Natural Language Semantics 12, 135-190.

Giorgi, A. and F. Pianesi (1997). Tense and aspect: From semantics to morphosyntax. Oxford: Oxford University Press.

Greenberg, Y. (2003). Manifestations of Genericity. New York: Routledge.

Klein, W. (1994). Time in language. London and New York: Routledge.

Kratzer, A. (1996). Severing the external argument from its verb. In J. Rooryck and L. Zaring (Eds.), Phrase Structure and the Lexicon, pp. 109-137. Dordrecht: Kluwer.

Kratzer, A. (1998). More structural analogies between pronouns and tenses. In D. Strolovitch and A. Lawson (Eds.), Proceedings of the 8th Semantics and Linguistic Theory Conference, pp. 92-110. Ithaca, NY: CLC Publications, Cornell University.

Kratzer, A. (2002). The event argument and the semantics of verbs. Unpublished manuscript, University of Massachusetts at Amherst.

Kratzer, A. (2008). On the plurality of verbs. In J. Dölling, T. Heyde-Zybatow, and M. Schäfer (Eds.), Event Structures in Linguistic Form and Interpretation, pp. 269-300. Berlin: Walter de Gruyter.

Krifka, M. (1989). Nominal reference, temporal constitution and quantification in event semantics. In R. Bartsch, J. van Benthem, and P. van Emde Boas (Eds.), Semantics and contextual expression, pp. 75-115. Dordrecht: Foris.

Krifka, M., F. Pelletier, G. Carlson, A. ter Meulen, G. Link, and G. Chierchia (1995). Genericity: An introduction. In G. Carlson and F. Pelletier (Eds.), The Generic Book, pp. 1-124. Chicago, IL: University of Chicago Press.

Landman, F. (1992). The progressive. Natural Language Semantics 1(1), 1-32.

Landman, F. (2000). Events and plurality: The Jerusalem lectures. Dordrecht: Kluwer.

Lewis, D. (1975). Adverbs of quantification. In E. Keenan (Ed.), Formal Semantics of Natural Language, pp. 3-15. Cambridge: Cambridge University Press.

Reichenbach, H. (1947). Elements of Symbolic Logic. New York: Macmillan.

Rimell, L. (2004). Habitual sentences and generic quantification. In V. Chand, A. Kelleher, A. J. Rodríguez, and B. Schmeiser (Eds.), Proceedings of the 23rd West Coast Conference on Formal Linguistics, pp. 663-676. Somerville, MA: Cascadilla Press.

Schein, B. (1993). Plurals and Events. Cambridge, MA: MIT Press.

von Stechow, A. (2009). Tenses in compositional semantics. In W. Klein and P. Li (Eds.), The Expression of Time, pp. 129-166. Berlin: Mouton de Gruyter. 